sequently discussed at length by the whole committee. "We tried to draw this [a commitment to accelerated approval requirements] out of the company," says Thorne. "The FDA is most comfortable when the sponsor makes a commitment in an open public hearing, so everyone is on the same page." Serono officials, however, were clearly confused by the discussion.

Some of the confusion is a result of the demands that the AIDS epidemic has placed on the FDA. "In many ways, the FDA has given a lot of latitude to AIDS drug approval," says Thorne. "They're trying to take a system that wasn't set up to get drugs out speedily and adapt it to meet life-threatening situations." This is particularly difficult for newcomers to the politically tumultuous world of AIDS drug approval such as Serono, whose representatives appeared unprepared for the intense scrutiny trained on their data during the committee meeting and the behind-the-scenes intrigue after the meeting.

However, it is clear that the data presented by the company to the advisory committee did not support full approval. The data were from two clinical trials of Serostim that used a gain in body weight (predominantly lean body mass) to determine efficacy. The first study showed an average gain of 1.6 kilograms in the study group over the control group, although there was some question as to the composition of that weight gain (which could be the result of intracellular water, protein or some other factor). The second study, however, failed to replicate the results of the first, although a secondary, "supportive" end point (a "quality-of-life" evaluation of the participants) demonstrated some benefit of Serostim treatment in this group.

This subjective "quality-of-life" benefit of Serostim treatment was emphasized during the open public discussion section of the hearings. "It was like Lourdes on a good day in there," one committee member said of the public testimony. "Everyone threw down their crutches, saying this [drug] was the best thing that has happened in AIDS treatment." Indeed, the only negative testimony at the open public discussion came from Paul Davis, a member of ACT-UP, Philadelphia, who took Serono to task for its "astronomical and obvious greed" in seeking approval for a drug many feel is overpriced, an issue not under consideration by the committee.
Despite the positive spin placed on the slender data by Serono representatives and the glowing testimony of most of the public participants, the FDA analysis of the data raised substantial questions. Besides the obvious fact that the second clinical trial did not clearly replicate the results of the first trial (thus failing to meet one of the conditions required by the FDA for any kind of approval), it was clear that the subset of patients who benefitted from the treatment was not adequately identified, which could make it difficult for physicians to decide who to treat with the drug. Committee members also raised concern about data that indicated that Serostim could increase HIV replication (although this could be controlled by antiviral treatment). Especially telling, in light of cost concerns and the hormonal side effects of the drug (such as raised levels of insulinlike growth factor) was the lack of studies to determine minimal effective dose or duration of dose.

Meanwhile, activists are trying to encourage other growth hormone manufacturers to seek approval for their products for treatment of wasting. "We are going to cooperate with anyone who wants to help people with wasting syn- drome have a longer and better life," says Thorne. "For example, if Genentech wants to get their act together and show a shortterm benefit to their growth hormone, we are more than willing to work with them." Matthew Sharp of Healing Alternatives in San Francisco, a group that helps test experimental treatments for wasting and has worked with Serono for five years to get Serostim approved, says that his group is frustrated enough to seek out other possibilities. "If we can find an as-effective [as Serostim] therapy for people, we'll go that route," he says. "We're not going to keep handing everything over to Serono."

Committee members who voted against approval were uncomfortable about the decision they were asked to make, but in the end it was clear only that Serostim likely offers some benefit to some people suffering from AIDS-related wasting. But just who those people are and how much Serostim can help them are questions still to be answered satisfactorily, according to the FDA and to most activists. In the meantime, the latter say the company should do what it takes to get accelerated approval, and work out the details for the studies necessary for full approval later.

FINTAN R. STEELE

\title{
Genentech sheds gp120 vaccine
}

Having already sunk an estimated US\$50 million into the development of recombinant gp120, a candidate vaccine for the prevention of HIV infection, Genentech, Inc., of South San Francisco announced in late February plans to spin off the project to form the basis of a new company whose sole focus will be HIV vaccine development, and in which Genentech has the right to retain a 25 percent stake. Genevax, as the new company will be called, will initially concentrate on kick-starting stalled efforts to conduct a pivotal phase III efficacy trial of gp120 in the United States and in Thailand where the AIDS epidemic is still raging despite an intensive public health campaign. The new, largely venture-backed company will be headed by Donald Francis, who was formerly in charge of the gp120 clinical trial program at Genentech.

Genentech's gp120 program in particular, and the AIDS vaccine business as a whole, suffered a serious setback in June, 1994, when the US National Institutes of
Health's National Institute of Allergy and Infectious Diseases (NIAID) pulled the plug on plans to back a large-scale efficacy trial in the United States of the two leading candidate gp120 vaccines (Genentech's and that of rival Chiron Corporation) on the grounds that these first-generation vaccines showed too little promise in preliminary safety and efficacy trials. Although NIAID, through its recently published strategy for HIV vaccine development, is now attempting to clarify the situation in the hopes of reestablishing links with industry, the scientific community is still divided over the relative merits of gp120 vaccines and over the logistical complexities of staging large-scale efficacy trials (Nature Medicine 1, 1105; 1995).

Whether or not NIAID's strategic plan has teeth, Genentech's decision to refocus its portfolio serves as a reminder that even an established company with relatively deep pockets must continually make value judgments about its product development pipeline. Development of 
an HIV vaccine "is an expensive, longterm effort of uncertain outcome at this point," says biotechnology analyst David Stone of Cowen \& Company in Boston. By creating a separate entity, however, Genentech is able to "keep the project alive in some fashion" and at the same time "make a better match between the nature of the investment and the investors."

In what Francis calls a "developmental partnership," Genentech will provide $\$ 1$ million in seed capital and a further $\$ 1$ million after Genevax raises at least an additional $\$ 18$ million from private investors. The task of attracting investor capital will fall to Robert Nowinski, a virologist-turned-entrepreneur, and Genevax's chairman. "If they had the money, they'd say they had it," says Stone, "so they're somewhere between having it and believing that they can [get it]." But as he points out, Nowinski has "been around the block a few times," having founded a number of biotechnology start-ups such as ICOS, Genetic Systems and PathoGenesis.

Contingent upon Genevax's ability to raise private funds, Genentech will hand over exclusive rights to the gp120 vaccine to Genevax, which will cover use of the vaccine and adjuvants, as well as access to preclinical and clinical data.
Moreover, Genentech staff scientists Philip Berman (immunology) and Tim Gregory (process science) will be on Genevax's scientific advisory board.

"The company's very simple," says Francis. "We're going to take MN [the Genentech gp120 vaccine] and do an efficacy trial with that in the United States and Thailand," with trials beginning early next year. Given that Genentech has stockpiled an estimated 300,000 doses of the $\mathrm{MN}$ vaccine, which contains HIV subtype-B antigens, Francis says "the $\$ 20$ million will allow us to do a phase III study only - no development of new antigens," an effort he estimates may cost another $\$ 10$ million. (Although almost all HIV-1 in the United States and Europe is subtype B, in Thailand both B and E subtypes are found, and in Asia and Africa non-B subtypes are mostly responsible.) Francis says that over the past year or so he sat down repeatedly with officials at Genentech to discuss how best to take the gp120 program beyond the earlystage clinical trials, during which time he was introduced to Nowinski by a mutual friend. Their personalities and skills were so complementary, according to Francis, that both saw "eye to eye on how to do it."

DIANE GERSHON

\section{DID YOU KNOW?}

\section{Making the most of managed care}

Consumers looking for information on managed health care plans may soon be assisted in their quest by a new program. The Agency for Health Care Policy and Research, a division of the US Department of Health and Human Services, has announced a cooperative effort to develop and conduct a consumer assessment of health-care plans and services.

The Consumer Assessment of Health Plans Study (CAHPS) is the result of a cooperation between the Research Triangle Institute, the RAND Corporation and Harvard University. CAHPS differs from previous studies in that it not only will look at overall consumer satisfaction with the different plan types, but also will include assessments of other areas such as access to care, reasons for using or not using particular plan services and the "hassle factor" associated with different plans.

Although not yet selected, several sites will be chosen for the initial implementation of the program. The ideal site, according to Christine Crofton, co-project officer of CAHPS, is one that exemplifies different service delivery settings. Work at the demonstration sites is expected to begin in early 1997.

HANNAH KERBY

\section{Outpatient tonsillectomy?}

During the 1950s, a tonsillectomy was considered a normal part of the American childhood experience. Despite the growth of antibiotic use for tonsil infection in the 1960 s, tonsillectomy is still the second most common childhood surgery, although there is substantial risk to the procedure (including heavy postoperative bleeding, severe sore throat and blocking of the airways). But now that risk may be substantially reduced, according to Mark S. Volk and colleagues at the Tufts University School of Medicine in Boston. Volk and colleagues have successfully performed a procedure on dogs they call MILTA (mucosal intact laser tonsillar ablation), which uses lasers to perform "incisionless tonsillectomies." MILTA causes the animals' tonsils to shrink and disappear within three weeks.

Despite the fact that humans trials of MILTA are at least a year away, Volk is optimistic that the simple procedure will eventually be done under local anaesthesia in a doctor's office. 